\title{
Formação de professores de língua estrangeira $x$ ensino intercultural - um desafio a ser superado nas letras
}

Vanessa Maria da Silva ${ }^{1}$

Resumo: A intercultura pode ser determinante para o êxito da interação comunicativa, proporcionando capacidades de negociação cultural que combinem comportamento curioso e consciente da necessidade de ultrapassar os estereótipos, com os conhecimentos linguísticos e culturais presentes na língua. A perspectiva intercultural contempla uma abordagem diferenciada do ensino de línguas estrangeiras (LE) favorecendo a consciência social, criatividade, mente aberta para novos conhecimentos e reforma na maneira de pensar e ver o outro. Nossa pesquisa com foco na formação de professores de língua estrangeira pelos Cursos de Letras, tem como objetivo investigar, se o ensino da cultura integra o ensino da LE. Procuramos analisar, por meio de um estudo documental, como os Cursos de Letras conceituadas universidades, do estado de São Paulo, preparam seu estudante, futuro professor, para reafirmar e desenvolver as propostas idealizadas pelos pesquisadores e teóricos que contemplam ensino de língua indissociável do ensino da cultura; como também para desempenharem, quando docente, os objetivos recomendados pelas Orientações Curriculares Nacionais, OCN, para o Ensino Médio. Nosso referencial teórico apoia-se em Byran (1997,1998), Hall (2004), Johnson (2009), Kramsch (2009), Risager (2007), dentre outros autores que defendem o ensino de LE a partir da perspectiva intercultural.

Palavras-chave: Língua. Cultura. Formação de Professores. Orientações Curriculares Nacionais.

\section{Foreign language teacher education versus intercultural teaching - a challenge to be met in the course of letters}

\begin{abstract}
Interculture can be crucial to the success of communicative interaction, providing cultural negotiating skills which combine curious and conscious behavior of the need to overcome the stereotypes, with linguistic and cultural knowledge present in the language. The intercultural perspective contemplates a differentiated approach about the teaching of foreign languages (FL) promoting social awareness, creativity, open mind to new knowledge and reform in the way of thinking and seeing the other. Our research focused on the graduation of foreign language teachers by Language University Courses, aims to investigate if the culture teaching integrates the teaching of FL. We analyzed by means of a documentary study, how Language Courses of renowned universities, in the state of São Paulo, prepare their student, a future teacher, in order to reaffirm and develop the proposals devised by researchers and theorists who understand as inseparable language teaching of cultural education; as well as to perform when teaching, the objectives recommended by the National
\end{abstract}

${ }^{1}$ Mestre doutoranda em Letras na Universidade Presbiteriana Mackenzie e-mail: vanessamariads@gmail.com 
Curriculum Guidelines (OCN) to high school. Our theoretical framework is supported by Byran (1997,1998), Hall (2004), Johnson (2009), Kramsch (2009), Risager (2007), among other authors who advocate teaching FL from the intercultural perspective.

Keywords: Language. Culture. Teacher Graduation. National Curriculum Guidelines.

\section{Considerações Iniciais}

O presente trabalho é um recorte da dissertação de mestrado Ensino de Língua e Estudo da Cultura: um Desafio aos Cursos de Letras na Formação de Professores, defendida em 2012, na Universidade Presbiteriana Mackenzie, São Paulo, SP. Trata-se de uma pesquisa qualitativa a qual investiga a formação de professores de Língua Inglesa pelos Cursos de Letras, tendo como objetivo pesquisar a formação do professor de língua inglesa como língua estrangeira, pelos cursos de Letras de duas renomadas universidades do Estado de São Paulo, Brasil. Investigamos a presença do ensino da cultura no ensino de língua inglesa, tanto nas disciplinas de Língua e Literatura, como nas disciplinas responsáveis pela preparação e formação do professor, pelos Cursos de Letras.

Esta pesquisa abarca como embasamento teórico estudos de renomados pesquisadores na área de Ensino de Língua Estrangeira como Claire Kramsch, Michael Byram, Alice Omaggio Hadley, entre outros, que compreendem língua e cultura como algo indissociável; defendem o ensino da língua estrangeira a partir de uma abordagem intercultural, que valoriza, além da competência comunicativa, o compartilhamento e a discussão de informações para que o aluno perceba que há uma heterogeneidade contextual, social, cultural e histórica no uso de qualquer linguagem. (BYRAM, GRIBKOVA; STARKEY, 1997).

A partir dessas considerações, ensinar uma Língua Estrangeira sem ensinar sua cultura acarreta um aprendizado incompleto e impreciso. Acredita-se que, ao aprender uma nova língua, o indivíduo poderá ampliar sua visão de mundo, uma vez que a aquisição de uma língua estrangeira pode auxiliar na constituição da autopercepção do indivíduo como ser humano e como cidadão. Conhecer uma 
cultura diferente é um preâmbulo para compreender e respeitar as pessoas dessa cultura e suas diferenças. Além disso, ao compreender o Outro, aprendemos mais sobre nós mesmos e sobre o que significa a pluralidade de mundos, perspectivas literárias, sociais e ideológicas, linguagens de profissões, épocas e períodos que estão impregnados no discurso do Outro.

Os estudos de Claire Kramsch com ênfase na importância de promover o ensino da cultura no ensino de línguas constituirá as bases em que se fundamentará este estudo. Uma vez que suas considerações apresentam como princípio linguístico básico para aprendizagem e ensino de língua estrangeira que a comunicação intercultural é um campo interdisciplinar de pesquisa, que estuda como as pessoas entendem uns aos outros para além das diversas fronteiras, sejam elas nacionais, geográficas, de classe, profissionais ou de gênero.

Para Kramsch, a relação estudo da cultura no ensino de língua está resumida nesta afirmação:

A questão que nos interessa aqui é a seguinte: uma vez que
desejamos ensinar línguas, de modo que os aprendizes sejam
introduzidos nos significados sociais e culturais, quantos desses
significados podem ser explicitados e quantos podem estar
implícitos? Como pode uma visão estrangeira de mundo ser
ensinada por um tipo de educação a qual, ela própria é o
produto de concepções e valores nativos? (KRAMSCH, 2001,
p.09)

No Brasil, conceitos discutidos na Linguística Aplicada sobre o componente cultural como elemento essencial no processo de ensino e aprendizagem de línguas têm permeado documentos oficiais sobre o ensino de língua estrangeira, dentre os quais destacamos as Orientações Curriculares Nacionais (OCN), uma referência curricular para Língua Estrangeira no Ensino Médio, elaboradas pelo Ministério da Educação e Secretaria de Educação Básica, em 2006, e que vigoram até os dias de

\footnotetext{
1 "The question that concerns us here is the following: given that we want to teach language in such a way that learners are initiated into its social and cultural meanings, how many of these meanings must be made explicit, how many can be understood implicitly? How can a foreign way of viewing the world be taught via an educational culture which is itself the product of native conceptions and values?" (KRAMSCH, 2008, p.09) Tradução da pesquisadora.
} 
hoje. As OCN contemplam o ensino de língua estrangeira contextualizada na formação global do aluno como forma de promover o desenvolvimento da consciência social, criatividade, abertura para conhecimentos novos e uma nova maneira de ver e pensar o mundo.

Dado o exposto, o presente trabalho investiga a presença do ensino da cultura no ensino de língua inglesa no curso de graduação em Letras em relação aos objetivos propostos aos docentes de Língua Estrangeira do Ensino Médio pelas Orientações Curriculares Nacionais (OCN).

Com o propósito de compreendermos essa interconexão (Estudo da Cultura Ensino de Língua Inglesa - Curso de Letras - OCN), decidimos analisar e estabelecer um paralelo entre os Planos de Ensino do Curso de Letras de duas conceituadas universidades do Estado de São Paulo, uma universidade privada, à qual nos referimos como Universidade $\mathrm{A}$, e uma universidade pública, à qual nos referimos como Universidade B. O nome das instituições foi suprimido, uma vez que não nos compete analisar as duas universidades e sim utilizar os Planos de Ensino das disciplinas que envolvem o ensino de Língua Estrangeira.

\section{Uma breve compreensão a respeito do liame entre Cultura e Língua}

De acordo com Lameiras (2006, p.29), relacionar cultura e ensino de línguas é reconhecer a importância que essa fusão exerce diante das representações sobre aprender e ensinar línguas, provocando no aprendiz uma abertura para o mundo do outro, ao mesmo tempo que visa reafirmar sua própria identidade cultural.

Pensando, antes de tudo, na etimologia do termo cultura, remontamos à sua origem latina e ao significado de 'cultivar o solo', 'cuidar'. Ao longo da história, porém, a definição desse termo tem motivado diversas discussões. No senso popular, ele é normalmente utilizado para designar aqueles indivíduos que tiveram acesso a uma escolarização ou que são considerados intelectuais; tais pessoas são chamadas de cultas. Isso decorre da herança da concepção clássica da palavra, segundo a qual “[...] constitui excelência em arte, literatura, maneiras e instituições sociais”. (LYONS, 
1987, p.223). Essa visão foi retomada, mais tarde, pelos renascentistas. Além disso, a palavra é também utilizada em referência às manifestações folclóricas, tidas como a cultura de determinado povo.

Em 1958, o acadêmico e novelista Raymond Williams escreveu a obra intitulada Cultura e Sociedade, em que observa a necessidade de enfatizar que cultura é aquilo que é comum ao homem e que, portanto, inclui os padrões de comportamento, o sistema de valores e a visão do mundo nos quais cada um de nós é aculturado desde o nascimento e durante a infância, na família e na sociedade. Para Williams, cultura é tudo o que forma o nosso comportamento espontâneo, em parte inconsciente, é tudo o que foi adquirido de modo natural e aprendido de modo formal, na escola, espaço laboratorial onde a vida e a natureza são simuladas e onde assumem a forma de experiências que se manipulam para serem compreendidas e controladas.

No final do século XVIII e início do seguinte, o termo germânico Kultur (Cultura) era utilizado para simbolizar todos os aspectos espirituais de uma comunidade, enquanto o francês Civilization (Civilização) referia-se às realizações materiais de um povo. Foi somente em 1871 que esses dois termos foram sintetizados no vocábulo inglês Culture (Cultura). O autor dessa síntese foi Edward Tylor, que trouxe, no primeiro parágrafo de seu livro Cultura Primitiva, a primeira definição de cultura formulada do ponto de vista antropológico:

[...] tomado em seu amplo sentido etnográfico é este todo complexo que inclui conhecimentos, crenças, arte, moral, leis, costumes ou qualquer outra capacidade ou hábitos adquiridos pelo homem como membro de uma sociedade. (1871 apud LARAIA, 2005, p.25)

Com esta definição, Tylor abrange, em uma única palavra, todas as possibilidades de realização humana, além de apontar o caráter de aprendizado da cultura, em oposição ao pensamento de aquisição inata, transmitida por mecanismos biológicos. Dito de outro modo, cultura abrange tudo o que o homem faz como 
membro de uma dada sociedade e que depende de uma forma qualquer de aprendizado. Como observa Claire Kramsch, uma maneira de entendermos cultura é contrastá-la com natureza (1998, p.4). A natureza é tudo que está em nós por hereditariedade biológica, o que nasce e cresce organicamente; cultura, por sua vez, refere-se a tudo que mantemos da tradição externa.

Na obra Cultura Primitiva, Edward Tylor demonstra que a cultura pode ser elemento de estudo sistemático, pois se trata de um fenômeno natural, que possui causas e regularidades, sendo, portanto, fenômeno aberto a um estudo objetivo e a uma análise capazes de proporcionar a formulação de leis sobre o processo cultural e a evolução.

O pensamento de Tylor pode ser melhor compreendido a partir deste trecho:

Por um lado, a uniformidade que tão largamente permeia entre civilizações pode ser atribuída, em grande parte, a uma uniformidade de ação de causas uniformes, enquanto, por outro lado, seus vários graus podem ser considerados como estágios de desenvolvimento ou evolução... (1871, apud LARAIA, 2005, p.30)

Quase um século após a definição apresentada por Tylor, encontramos em Kroeber $(1950)^{2}$ expressiva colaboração para a ampliação do conceito de cultura; ela é apontada como um processo resultante de toda experiência histórica das gerações anteriores, uma vez que toda a experiência de um indivíduo é transmitida aos demais, criando, assim, um interminável processo de acumulação, o qual se dá graças ao ato da comunicação. Assim sendo, a comunicação é um produto cultural, ou, mais especificamente, a linguagem humana é um produto da cultura. Segundo Laraia (2005, p.52), não existiria cultura se o homem não tivesse a possibilidade de desenvolver um sistema articulado de comunicação.

\footnotetext{
${ }^{2}$ Alfred Louis Kroeber foi um dos fundadores da Associação Antropológica Americana e seu presidente em 1917. Antes, em 1906, já havia presidido a Sociedade de Folclore Americano e depois, em 1940, veio a presidir a Sociedade Linguística da América. Após formar-se em inglês pela Universidade de Columbia, em 1897, estudou Antropologia com Franz Boas.
} 
Importante apontarmos que a participação do indivíduo em sua cultura é sempre limitada, pois ninguém é capaz de compartilhar ativamente e dominar todos os aspectos de sua cultura. Como afirmou Marion Levy Jr., ${ }^{3}$

nenhum sistema de socialização é idealmente perfeito, em nenhuma sociedade são todos os indivíduos igualmente bem socializados, e ninguém é perfeitamente socializado. Um indivíduo não pode ser igualmente familiarizado com todos os aspectos de sua sociedade; pelo contrário, ele pode permanecer completamente ignorante a respeito de alguns aspectos (1952 apud LARAIA, 2005, p.82)

O essencial, porém, é que deve haver um mínimo de participação do indivíduo na pauta de conhecimento da cultura a fim de possibilitar a sua articulação com os demais membros da sociedade (LARAIA, 2005, p.82). Todos necessitam saber como agir em determinadas situações e, também, como prever o comportamento dos outros. A coerência de um hábito cultural somente pode ser analisada a partir do sistema a que pertence. Cada sistema cultural está em permanente mudança. Compreender esta dinâmica é fundamental para atenuar o choque entre gerações e evitar manifestações preconceituosas. Da mesma forma que é importante para a humanidade o entendimento das diferenças entre povos de culturas diferentes, é necessário saber entender as diferenças presentes dentro de um mesmo sistema. Este é um dos principais processos que preparam o indivíduo para descortinar o mundo.

O conceito de cultura inclui a língua, a história, a geografia, os modos de formular ideias, de fazer, de ser e de estar comuns aos membros de um mesmo grupo social; inclui um espaço compartilhado; uma visão do mundo e uma simbologia veiculada.

Tomando como base o conceito antropológico, podemos considerar que tratar de língua significa, entre outras coisas, tratar de um produto da cultura de cada povo. Através da língua são identificados os hábitos, crenças, profissões,

\footnotetext{
${ }^{3}$ Marion Joseph Levy Jr., sociólogo norte-americano, notório pelo seu trabalho na Teoria da Modernização.
} 
manifestações culturais, características geográficas etc. de cada comunidade linguística.

O aprendizado de uma língua consiste não apenas no entendimento e domínio de sua estrutura gramatical, mas também na coerência entre o que ela descreve e o conhecimento de mundo que seu falante possui. Essa necessidade se dá tanto na aprendizagem de línguas estrangeiras quanto no processo de alfabetização em língua materna. O indivíduo, para poder ler e compreender completamente uma palavra, primeiramente terá de conhecer o referido objeto - a referência. Senão, o discurso será, para ele, incoerente.

A partir dessas considerações a respeito de cultura, é importante para o desenvolvimento do nosso trabalho compreender o que Brown considera intricately interwined $^{4}$ entre o processo de ensinar língua e estudar a cultura da língua-alvo. Por meio da língua expressamos nossos pensamentos e descrevemos o mundo que nos cerca. Portanto, utilizar um léxico cujos significantes são desconhecidos pelo estudante de língua estrangeira consiste em reproduzir um discurso que lhe é “abstrato". Desse modo, o aprendiz de língua estrangeira se depara com duas dificuldades: aprender uma nova estrutura linguística e conceber um novo paradigma de mundo.

Como afirma Lameiras (2006, p.34), “devemos cuidar para que o aprendiz de LE, ao se deparar com os sons, as formas e os sentidos de outra língua, não se sinta tal qual um viandante ao percorrer terras estranhas, sentindo-se, literalmente, um estrangeiro."

Uma língua é a ponte que une os membros de uma sociedade e a sua cultura, de múltiplas e complexas maneiras. Além disso, segundo Claire Kramsch a língua que falamos, a escolha de palavras que utilizamos em nosso discurso, tudo isso revela, através do nosso dialeto, de nossa linguagem, quem somos, de onde viemos,

${ }^{4}$ Intricadamente entrelaçadas [tradução nossa] 
nossa personalidade e nossas intenções. “A língua é um importante meio pelo qual conduzimos nossa vida social" (KRAMSCH, 1998, p.3).

Com o propósito de compreender uma outra língua, não é suficiente dominar isoladamente o conjunto léxico-gramatical do outro idioma, mas entender, especificamente, como observa Kramsch (1998, p.25), o contexto de situação; o ambiente físico, temporal e social no qual as trocas verbais ocorrem, assim como é necessário entender também o contexto histórico-cultural, as crenças, atitudes, organização social e valores compartilhados pelos membros de uma mesma comunidade discursiva, para o melhor entendimento do significado de suas trocas verbais. O significado não é criado apenas através do que os interlocutores falam, mas principalmente do que fazem com as palavras.

Enfim, a relação entre língua e cultura tem recebido, no mundo todo, respeitável notoriedade e é tema recorrente em discussões, uma vez que, como já citado anteriormente, a língua é o principal meio pelo qual conduzimos nossa vida social, estando intensamente relacionada ao nosso pensamento e nosso comportamento, bem como ao modo como influenciamos o comportamento dos outros. Hanna (2001, p. 90) comenta que tal constatação remete ao campo da interculturalidade, pois o foco da comunicação é a interação entre pessoas de culturas diferentes, acarretando, em consequência, a reflexão sobre nossa própria vida e nosso relacionamento com povos de outras línguas e cultura.

De acordo com L. Porcher (2004, p. 117) o prefixo "inter-“ é responsável por atribuir peso à palavra interculturalidade por justamente enfatizar o aspecto relacional, as interações entre identidades, indivíduos e grupos implicando reciprocidade, eliminação de barreiras, enfatizando a percepção de como eu vejo o outro e de como nós nos vemos por meio das relações estabelecidas entre eu e o outro. A perspectiva intercultural parte de uma multiplicidade de identidades, e concentra-se na utilização das culturas e das reivindicações identitárias em interação para analisar as situações de encontros e discursos interculturais. 
Compreende-se, então, que desenvolver uma prática intercultural no ensino de língua significa adotar aspectos ou informações da cultura do idioma que está sendo ensinado como forma de promover a troca de informações entre culturas. Barbosa $(2007$, p. 113) destaca que a perspectiva intercultural também pode ser vista como "um procedimento ou uma ação que auxilia o aprendente a perceber as configurações identitárias e culturais de forma problematizadora e nãosimplificada". Desse modo, essa abordagem se configura como uma maneira nova de se "ver" e estudar a língua estrangeira.

O ponto de partida para um ensino intercultural, de acordo com Fleuri (2001), está em o professor deixar de transmitir para o aluno uma cultura homogênea e coesa, e passar a preocupar-se com diversidade de modelos culturais que interagem na formação do conhecimento dos estudantes, ou seja, estimular meios para que o estudante "veja" a cultura do outro como heterogênea, e ao mesmo tempo, integradora de sua própria cultura. Sendo assim, através da perspectiva intercultural o aprendiz de línguas reflete acerca de sua própria cultura, bem como é levado a estimular a consciência das diferenças e das relações entre culturas (TEIXEIRA, 2012).

O papel do professor de língua estrangeira, no espaço intercultural do processo ensino e aprendizagem, é substancial pois, através dele, o estudante será instrumentalizado pela multiplicidade cultural da língua estrangeira estudada. Quando se fala em interculturalidade, não se pode deixar de mencionar no âmbito das práticas educacionais, o que Fleuri enfatiza:

[...] em nível das práticas educacionais, a perspectiva intercultural propõe novas estratégias de relação entre sujeitos e entre grupos diferentes. Busca promover a construção de identidades sociais e o reconhecimento das diferenças culturais. Mas, ao mesmo tempo, procura sustentar a relação crítica e solidária entre elas (2001, p. 113).

Nesse sentido, percebe-se que a perspectiva intercultural, ao ser desenvolvida como prática em sala de aula, pode proporcionar uma relação entre línguas, pois esta relação possibilita ao aprendiz olhar para a cultura do outro percebendo as 
diferenças, tanto identitárias quanto culturais, de tal maneira que se respeite, conheça e aceite a cultura do outro. Dado que, quando se faz uma relação entre as culturas, a formação do estudante será desenvolvida e construída em um âmbito que engloba a consciência crítica de diferentes contextos sócio-históricos.

Acreditando em um ensino de língua associado às questões relativas à cultura na constituição das representações de aprender e ensinar línguas, como práticas socioculturais, discorremos a respeito da perspectiva intercultural, que possibilita ao novo conhecimento linguístico ser acrescido da percepção de novas culturas e de novas concepções de vida.

Logo a proposta deste trabalho é mostrar a necessidade do estudo da cultura para assim possibilitar uma melhor e efetiva troca de comunicação àqueles que serão os responsáveis em ensinar uma língua estrangeira aos seus futuros alunos de acordo com as propostas das Orientações Curriculares Nacionais.

\section{Pesquisa qualitativa: os Planos de Ensino}

Edward Sapir descreve que uma língua e a cultura de seu falante não podem ser analisadas isoladamente. Para Sapir, língua pode ser compreendida como uma maneira de descrever e representar a experiência humana e a sua concepção de mundo (SAPIR, 1921 apud HINKEL, 1999, p.03).

Para Claire Kramsch, o estudo da cultura no ensino de língua é frequentemente reduzido ao que, em inglês, se chama "the four Fs: food, fairs, folklore, and statistical facts" (Os quatro Fs: comida, mercado, folclore e fatos estatísticos) (1991, p.218). A autora enfatiza, no entanto, que o estudo da cultura no ensino de língua é muito mais complexo que "the four Fs" e que o ensino de língua precisa correlacionar "o ensino de língua à sua cultura" (1991, p.236).

Em sua obra Context and Culture in Language Teaching, de 2001, ela afirma que o estudo da cultura, explicita ou implicitamente, permeia o ensino da interação social, bem como os objetivos propostos aos professores do Ensino Médio pelas Orientações Curriculares Nacionais. As OCN propõem que o ensino de Língua Estrangeira 
ofereça aos alunos uma nova visão de mundo, que inclui o desenvolvimento de consciência social.

Dado o exposto, a presente pesquisa investiga a presença do estudo da cultura no ensino de Língua Inglesa no curso de graduação em Letras em relação aos objetivos propostos aos docentes de Língua Estrangeira do Ensino Médio pelas Orientações Curriculares Nacionais (OCN).

Com o propósito de compreendermos essa interconexão (Estudo da Cultura Ensino de Língua Inglesa - Curso de Letras - OCN), decidimos analisar e estabelecer um paralelo entre os Planos de Ensino do Curso de Letras de duas conceituadas universidades do Estado de São Paulo, uma universidade privada, à qual nos referimos como Universidade $\mathrm{A}$, e uma universidade pública, à qual nos referimos como Universidade B. O nome das instituições foi suprimido, uma vez que não nos compete analisar as duas universidades e sim utilizar os Planos de Ensino das disciplinas que envolvem o ensino de Língua Estrangeira.

Como a pesquisa aborda o ensino de Língua Estrangeira com foco na língua inglesa, optamos pelas seguintes disciplinas obrigatórias:

Língua Inglesa;

Literatura Inglesa;

Literatura Norte-Americana;

Metodologia do Ensino de Língua Inglesa e

Estágio Supervisionado em Língua Inglesa

É importante salientar que os nomes atribuídos às disciplinas divergem de uma Universidade para outra, assim como difere a distribuição das disciplinas ao longo do curso, ora algumas disciplinas são desenvolvidas por semestre, ora são anuais. Notemos que nosso trabalho tem foco no conteúdo de cada disciplina e não em sua periodicidade, como podemos observar no quadro a seguir: 


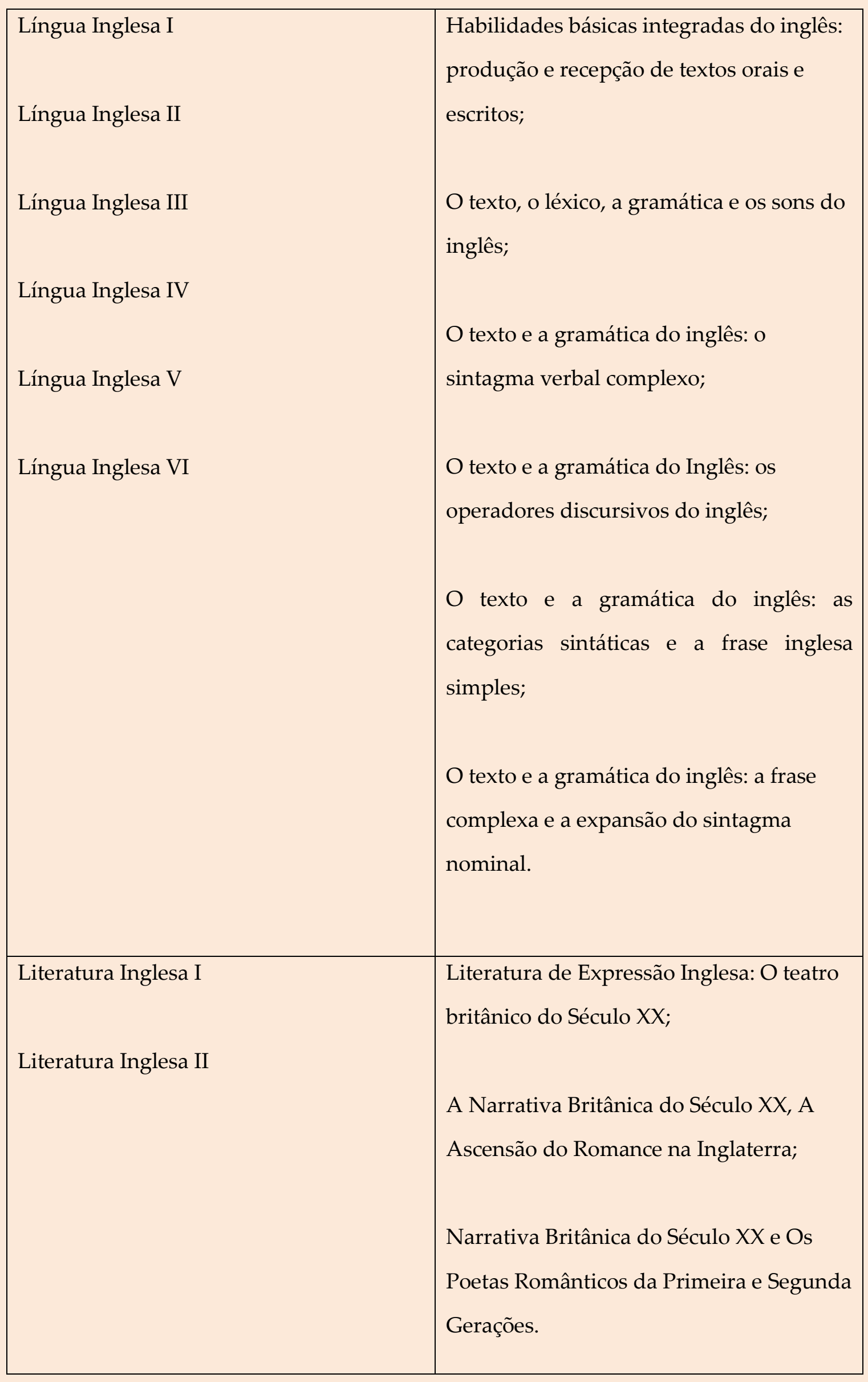




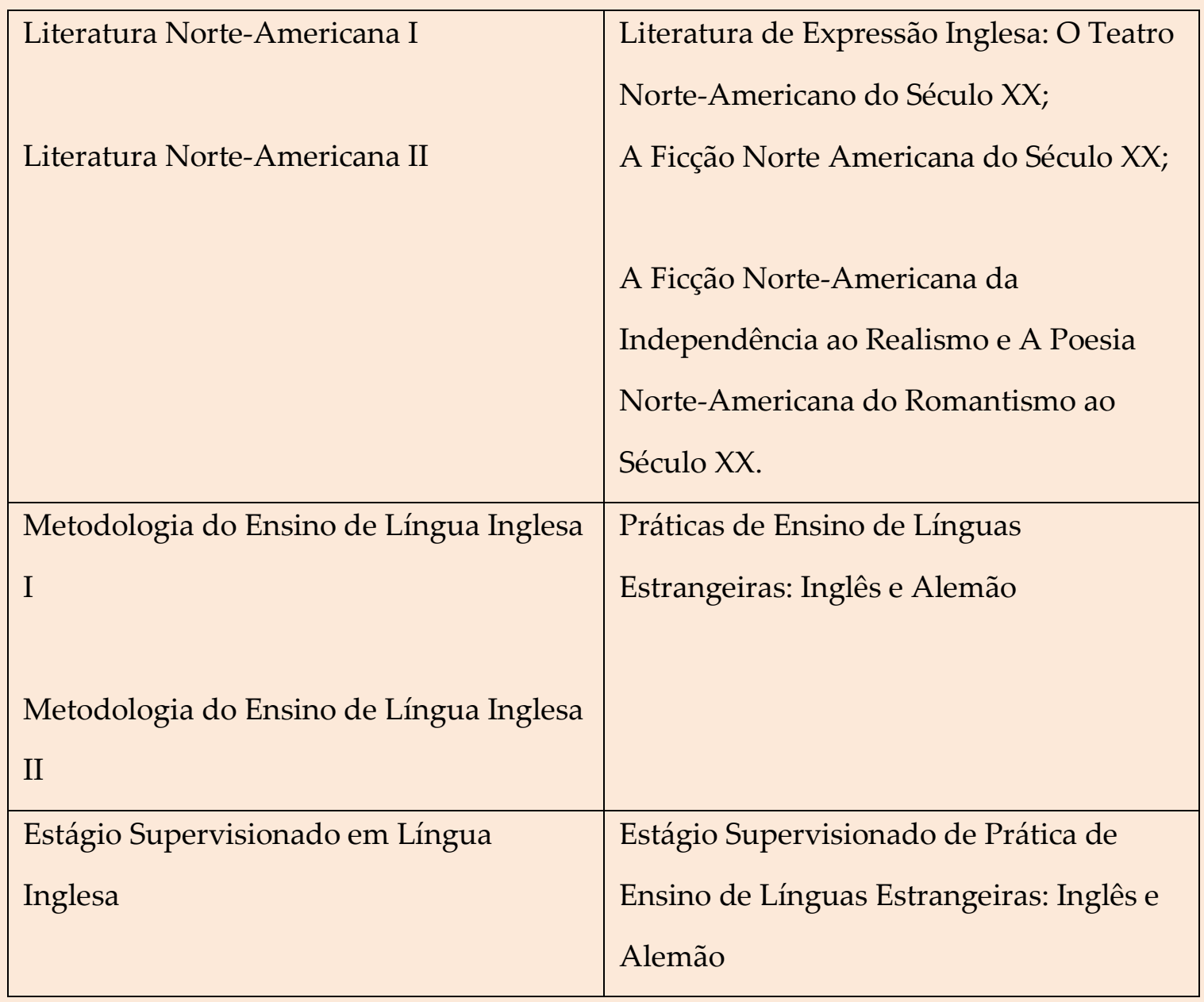

Nossa análise investiga, nos Planos de Ensino daquelas disciplinas, primeiramente a ocorrência ou não ocorrência de termos relacionados à cultura, como estudo da cultura, aspectos culturais, componentes pragmático-cultural e linguísticocultural, contexto sociocultural e histórico cultural, contracultura, interculturalidade. Além disso, procura saber se os Planos de Ensino demonstram a devida importância e interesse pelo contexto cultural. Enfatizamos ainda que nosso trabalho também investiga termos que possam, de certa forma, expressar uma relação com o estudo da cultura, tais como contexto histórico-social, produtos históricos, perspectivas políticas e ideológicas.

Nos Planos de Ensino de cada disciplina, analisamos os seguintes itens: Objetivos, Ementa e Bibliografia Básica. A escolha desses itens se dá pela relevância de cada um: no item Objetivos, que funcionam como horizonte e alicerce da prática, podemos saber os propósitos da ação. Os objetivos são expressos por meio de verbos 
no infinitivo e traduzem os comportamentos, habilidades, atitudes e competências esperadas dos alunos. A Ementa é uma descrição discursiva que sintetiza o conteúdo conceitual ou procedimental de uma disciplina. No item Bibliografia Básica, encontramos as indicações de livros, textos e autores de determinado assunto relacionado aos objetivos propostos; fontes a partir das quais os estudos serão realizados.

\section{Considerações finais}

Buscamos, nesta pesquisa, tecer considerações acerca da questão do ensino da Cultura no processo de ensino de Língua Estrangeira, aqui, Língua Inglesa, no Curso de Letras. Pretendemos, com isso, contribuir para uma melhor compreensão de como esta interconexão acontece de maneira efetiva na formação do futuro professor, para que, desse modo, as Universidades e os profissionais envolvidos nesse complexo processo possam refletir sobre o currículo do curso e o planejamento das disciplinas e, além disso, fiquem de acordo com as normas do MEC.

Após a análise criteriosa dos documentos desenvolvida para esta pesquisa, revelou-se o predomínio de currículos estabelecidos de forma tradicional. Ao analisarmos a disciplina Língua Inglesa observamos que os Planos de Ensino das duas Universidades aqui investigadas apontam para uma seleção de bibliografias tradicionais e restritas ao conteúdo gramatical, o que nos leva a entender as aulas como meramente expositivas, com resolução de exercícios de fixação.

Contata-se, então, que quanto à disciplina observamos que é comum não apresentarem coerência entre os Objetivos e as Bibliografias, ou seja, a teoria não dialoga com a prática. Enquanto os Objetivos da disciplina Língua Inglesa, por vezes provem o estudo da cultura, as indicações bibliográficas se limitam à livros de gramática e dicionários.

A respeito do ensino das Literaturas, se por um lado a incidência do estudo da Cultura parece pouco profunda quando se analisa o ensino de língua, no que diz respeito às indicações bibliográficas, há uma compensação no ensino das literaturas 
de língua inglesa, contudo, voltados apenas para Literatura Inglesa e NorteAmericana. Não encontramos em nenhum dos Planos analisados indicação de estudo de outras literaturas de língua inglesa, como africana, indiana, caribenha, entre outras.

No que se refere aos Planos de Ensino das disciplinas Metodologia do Ensino de Língua Inglesa e Estágio Supervisionado de Língua Inglesa, vemos seu conteúdo prejudicado pela redução da carga horária estabelecida pelo MEC, ou seja, mesmo que o ensino da Cultura esteja presente nos Objetivos destas disciplinas seu trabalho fica comprometido devido à dificuldade de um tempo não satisfatório para desenvolvê-lo de forma significativa.

Ressalta-se também que, ao longo dos anos, as constantes mudanças efetuadas pelo governo por meio de leis e diretrizes não permitem que os Cursos de Letras adotem um perfil mais flexível para o ensino de Língua Estrangeira.

Reconhecemos que os Planos de Ensino deveriam ter como base o conhecimento da realidade para adequar-se às necessidades e possibilidades dos alunos dos Cursos de Letras, para que estes quando docentes alcancem os objetivos promovidos pelas OCN sobre a interconexão do Ensino de Língua Estrangeira e Ensino da Cultura. Serem flexíveis e abertos para permitirem a participação de todos os interessados e possibilitarem ajustes sempre que necessário. Constatamos ainda que os Planos de Ensino deveriam constituir um perfil exequível, ou seja, executável, no que se refere ao ensino da Cultura em um determinado tempo-duração, centrado no cerne de que o aluno do Curso de Letras será um futuro professor de Língua.

Posteriormente à minuciosa análise dos Planos de Ensino dessas duas universidades, podemos concluir que o ensino da Cultura no ensino de língua ainda é pouco desenvolvido, mesmo que os termos relacionados à cultura apareçam nos documentos, observamos pelas indicações bibliográficas a resistência ao ensino da cultura, razões essas que somente os professores ou os responsáveis pela elaboração dos Planos de Ensino poderiam alterar. As indicações bibliográficas geram uma contradição aos Objetivos e a Ementa dos Planos de Ensino. 
Verificamos que há, ainda que breve, o interesse no ensino da Cultura, pelo menos ele é apontado através dos termos relacionados à cultura, contudo observamos uma dificuldade em associar cultura à língua de uma maneira mais concreta. Encontramos a língua ensinada de uma forma mecânica, no qual apenas o léxico e os aspectos linguísticos que envolvem a língua são valorizados, deixando de lado a compreensão de que língua é um produto da manifestação cultural de um povo. Conhecer e falar uma determinada língua não implica apenas adquirir regras gramaticais e vocabulário, mas saber que há muito mais conteúdo envolvendo cada expressão, léxico, aspecto linguístico, isto é, há a cultura de um povo.

Observamos, desta maneira, que a formação de professores pelos Cursos de Letras em relação à importância do ensino da cultura no ensino de língua tem muito a progredir e a aperfeiçoar.

Sabemos que trabalhar com Cultura em sala de aula, ou seja, promover o ensino da Cultura no ensino de língua é pisar em terreno movediço, dada a complexidade que norteia os conceitos de cultura, no entanto, é indispensável que os Cursos de Letras assumam este desafio, para em fim, podermos contar com professores que contemplam a relevância do conhecimento cultural para promover aos seus alunos de Língua Estrangeira o desenvolvimento da consciência social, criatividade, abertura para conhecimentos novos e uma nova maneira de ver o mundo.

Reconhecemos que o Ensino da Cultura trata-se de uma proposta desafiadora ao Ensino de Língua nos Cursos de Letras para a formação de professores e acreditamos que há muito a se desenvolver sobre o emprego desta interconexão no contexto de sala de aula de uma Universidade. Uma vez que, muito mais que diretrizes de ensino, é necessário repensar o ensino de LE e sua ação no aprendizado dos estudantes e, consequentemente, na formação dos futuros professores pelos Cursos de Letras.

Nesse sentido, esperamos que nossas colocações contribuam com os alunos dos Cursos de Letras, futuros professores de Língua Estrangeira, com as próprias 
Instituições de Ensino e seus profissionais; para que possam compreender a relevância do aspecto cultural em Língua Estrangeira, uma vez que ao aprender e ensinar língua e cultura, o educador contribui na formação de cidadãos preparandoos para o desenvolvimento da consciência social e uma reforma na maneira de pensar e ver o mundo.

\section{Referências}

BECHARA Evanildo. Estrangeirismos são cada vez mais presentes na língua portuguesa. Espaço Aberto. Globo News, 27 de abril de 2011. Entrevista a Alexandre Garcia. BRASIL. Orientações Curriculares Nacionais. Conhecimento de Línguas Estrangeiras. Brasil, 2006.

http://portal.mec.gov.br/seb/arquivos/pdf/book volume 01 internet.pdf Acesso em $20 / 08 / 2011$.

BROWN, Douglas. H. Teaching by Principles - An Interactive Approach to Language Pedagogy. 3rd edition. New Jersey: Prentice Hall Regents. 1994.

BURRIDGE, Kate. Blooming English - Observations on the roots, cultivation and hybrids of the English language. Cambridge University Press, 2004.

BYRAM, Michael. MORGAN, Carol. Teaching-and-Learning Language-and-Culture. Clevedon: Multilingual Matters, 1994.

Michael. Teaching and Learning language and culture. Clevedon: Multilingual Matters,1994.

Michael. Teaching and Assessing Intercultural Communicative Competence.

Clevedon: Multicultural Matters, 1997. Michael \& FLEMING, Michael. Language Learning in Intercultural

Perspective. New York: Cambridge University Press, 1998.

CIAMPA, A.C. A Estória do Severino e a História da Severina. São Paulo: Brasiliense, 1987. 
CORBETT, J. An Intercultural Approach to English Language Teaching. Clevedon: Multilingual Matters, 2003.

CRYSTAL, David. English as a Global Language. New York: Cambridge University Press, 2001.

HADLEY, A. O. Teaching Language in Context. Boston: Heinle and Heinle Publishers, 1986.

HALL, J.K. Teaching and Researching Language and Culture. Pearson Education Limited. England. 2011.

HANNA, V.L.H. Autenticidade e cultura num parendizado significativo: contribuição para uma metodologia do ensino de inglês como língua estrangeira numa abordagem comunicativa. Dissertação. (Mestrado em Educação, Arte e História da Cultura) Universidade Presbiteriana Mackenzie, São Paulo, 2001. - Reflexões Sobre A Trajetória Do Ensino de Linguas Estrangeiras no Brasil. Revista do GEL, São Paulo, v.6, n.2, p.207-231, 2009.

HINKEL, E. Culture in second language teaching and learning. Cambridge: Cambridge University Press, 1999

HOLLIDAY, Adrian; HYDE, Martin e KULLMAN, John. Intercultural Communication. London and New York: Routledge, 2004.

JOHNSON, K.E. Second Language Teacher Education, A Socialcultural Persperctive. Routledge, New York, 2009.

LAMEIRAS, Maria Stela Torres Barros. Ensino de Lingua x Cultura: em busca de um aprendiz artesão, autônomo e cidadão. In: TAVARES, Roseanne Rocha (Org.) Língua, Cultura e Ensino. Maceió: UFAL, 2006.

LARAIA, R.B..Cultura - Um Conceito Antropológico. Rio de Janeiro: Jorge Zahar, 2005.

LEFFA, V.J. O Ensino de Inglês no Futuro: da Dicotomia para a Convergência. In:

STEVENS, C.M.T.; Caminhos e Colheita: Ensino e Pesquisa na área de inglês no Brasil.

Brasília: Editora UnB, 2003.

LYONS, John. Linguagem e Linguística: uma introdução. Rio de Janeiro: LTC, 1987. 
KATZ, S. e BLYTH, C. S. What is grammar? Em S. Katz and J. Watzinger - Tharp (Eds.). Conceptions of L2 grammar: Theoretical approaches and their application in the L2 classroom (pp. 2-14). Boston: Heinle Cengage Learning, 2008.

KRAMSCH, Claire. Language and Culture. Oxford: Oxford University Press. 1998. Claire. Context and Culture in Language Teaching. Oxford: Oxford University Press. 2001.

Culture in language teaching. In: BROWN, K. (Ed.). Encyclopedia of Language and Linguistics. Vol. 3. 2nd edition. Oxford: Elsevier Science, 2006a. p. 322-329.

From communicative competence to symbolic competence. The Modern LanguageJournal, v. 90, n. 2, p. 249 - 252, 2006 b.

The multilingual subject. What language learners say about their experience and why it matters. Oxford: Oxford University Press, 2009a.

. Cultural perspectives on language learning and teaching. In: KNAPP, K.; SEIDLHOFER, B. (Eds.). Handbook of foreign language communication and learning. Berlin: Mouton de Gruyter, 2009b. p. 219-245.

The symbolic dimensions of the intercultural. Language Teaching, Cambridge University Press, v. 44, p. 354-367, July 2011. Disponível em: http://journals.cambridge.org/action/displayAbstract?fromPage=onlineEaid $=8271738$ Acesso em: 20/03/2014.

RICHARDS, Jack C. Culture in Second Language Teaching and Learning. Cambridge: Eli Hinkel, 1999.

RISAGER, K. Language and Culture Pedagogy: from a national to a transnational paradigm. Clevedon: Multilingual Matters, 2007.

SILVA, Vanessa Maria da. Ensino de Língua e Estudo da Cultura: um desafio aos cursos de letras na formação de professores. 2011. 118 f.: Dissertação (mestrado) - Universidade Presbiteriana Mackenzie, São Paulo, 2011.

TEIXEIRA, C.S. Perspectiva Intercultural no Ensino de Linguas. Revista Litteris, no 9, Março de 2012 (p.283-294)

TYLOR, Edward. Primitive Culture. London/New York: Harper Torchbooks, 1958. 
VALDES, Joyce Merri. Culture Bound, Bridging the Cultural Gaps in Language Teaching. Cambridge: Cambridge University Press.1986.

WILLIAMS, Raymond. Culture is Ordinary 1780-1950. New York: Columbia University Press. 1983.

Recebido: em 27 de agosto de 2015

Aceito: em 24 de outubro de 2015 